\title{
PENGARUH REDUKSI CANAI TERHADAP SIFAT MEKANIS BAJA KARBON RENDAH DENGAN SAMBUNGAN FLASH BUTT WELDING
}

\author{
Sunardi, Ipick Setiawan, Fransisco Situmeang \\ Jurusan Teknik Mesin, Universitas Sultan Ageng Tirtayasa \\ Jl. Jendral Sudirman KM 03 Cilegon - Indonesia 42435 \\ Email : sunardi@untirta.ac.id
}

\begin{abstract}
ABSTRAK
Pembuatan pelat baja dapat dilakukan dengan metode canai panas dan dingin. Untuk memperoleh hasil yang optimal, maka rangkaian produksinya harus dilakukan secara kontinu pada cold rolling mill (CRM). CRM ini dilengkapi dengan flash butt welding machine yang berfungsi untuk menyambung antara satu pelat dengan pelat lainnya. Penelitian ini dimaksudkan untuk mengetahui perubahan sifat mekanis pada baja pelat yang mengalami reduksi selama proses canai. Metode yang digunakan dalam penelitian ini bersifat eksperimental yakni pengukuran pada daerah lasan, daerah pengaruh panas (HAZ) dan material induk. Reduksi canai yang digunakan adalah reduksi $0 \%, 69,78 \%, 71,56 \%$ dan 73,33\%. Karakteristik material yang diamati adalah kekerasan, kekuatan tarik, kekuatan luluh, elaongasi dan laju korosinya. Dari penelitian ini diketahui bahwa reduksi canai $73,33 \%$ menghasilkan perubahan sifat mekanis yang paling baik. Nilai kekerasan, kekuatan tarik, kekuatan luluh dan laju korosi berturut-turut adalah $82,26 \mathrm{HRB}, 644 \mathrm{~N} / \mathrm{mm}^{2}, 501 \mathrm{~N} / \mathrm{mm}^{2}$ dan 1,3844 mpy.
\end{abstract}

Kata kunci : canai dingin, reduksi tebal, sifat mekanis, laju korosi

\begin{abstract}
Steel plate making can be produced by hot and cold rolling method. To obtain the optimal results, the production on the cold rolling mill (CRM) must be carried out continuously. This CRM is equipped with a flash butt welding machine to connect between one plate and anothers. The purpose of this research is to determine the effect of thickness reduction on mechanical properties of steel JIS 3141. The method used in this study is experimental, namely mechanical properties testing at weld area, heat affected zone (HAZ) and base material. The thickness reductions used in this research are $0 \%, 69,78 \%, 71,56 \%$ and 73,33\%. The material characteristics observed were hardness, tensile strength, yield strength, elaongation and corrosion rate. From this study it is known that the thickness reduction $73.33 \%$ resulted the best mechanical properties. The values of hardness, tensile strength, yield strength and corrosion rate were $82.26 \mathrm{HRB}, 644 \mathrm{~N} / \mathrm{mm}^{2}, 501 \mathrm{~N} / \mathrm{mm}^{2}$ and $1.3844 \mathrm{mpy}$, respectively.
\end{abstract}

Kata kunci : cold rolling, thickness reduction, mechanical properties, corrosion rate

\section{PENDAHULUAN}

Canai adalah proses penipisan atau pelenturan dengan memanfaatkan sifat plastis material. Proses ini bertujuan untuk memperoleh ketebalan pelat tertentu atau membentuk pelat dengan diameter kelengkungan yang diinginkan. Peralatan canai secara umum terdiri dari rumah dan dudukan canai, perangkat bantalan canai, dan alat pengatur. Canai dapat diklasifikan menjadi dua macam, yaitu canai utama (work roll) dan canai pendukung (back up roll). Canai utama adalah bagian yang langsung berinteraksi dengan benda kerja. Pengurangan ketebalan pelat sangat dipengaruhi oleh gaya gesek antara canai dengan material. Canai pendukung berfungsi untuk menahan kerja canai utama dan mendistribusikan gaya yang diperlukan selama proses deformasi pada canai utama.

Reduksi ketebalan pelat semakin tinggi maka kekuatan dan kekerasan material mengalami peningkatan, tetapi berkebalikan terhadap keuletannya. Dari penelitian ini menunjukkan bahwa semakin tinggi persentase reduksi maka performa balistik untuk amunisi meningkat secara signifikan $^{[1]}$.

Peningkatan kekerasan, kekuatan luluh dan kekuatan tarik seiring dengan peningkatan deformasi dingin. Canai dingin 30\% yang diikuti dengan solution treatment menghasilkan kombinasi antara keuletan dan kekuatan yang sangat baik. Pemberian solution treatment pada suhu $1020^{\circ} \mathrm{C}$

36 Sunardi, dkk; Pengaruh Reduksi Canai Terhadap Sifat Mekanis Baja Karbon Rendah Dengan Sambungan Flash Butt Welding 
selama 30 menit menyebabkan terjadinya pembentukan butir austenite yang hampir seragam $^{[2]}$.

Kombinasi antara pengerjaan dingin dan sandblasting pada baja stainless steel 316L mampu meningkatkan perilaku mekanis material, akan tetapi proses sandblasting justru menurunkan ketahanan korosinya dan permukaan yang dihasilkan lebih kasar $^{[3]}$. Proses tempa (forging) yang diberikan pada material baja stainless 316L akan mempengaruhi perubahan sifat mekanisnya. Semakin tipis material hasil tempa semakin tinggi kekerasan dan kekuatan tariknya ${ }^{[4]}$.

Pengelasan adalah proses penyambungan beberapa logam menjadi satu akibat panas dengan atau tanpa pengaruh tekanan. Flash butt welding (FBW) merupakan metode pengelasan yang dilakukan dengan menggabungkan antara loncatan elektron dengan tekanan, di mana benda kerja yang dilas dipanasi dengan energi loncatan elektron kemudian ditekan sehingga bahan yang dilas dapat menyatu dengan baik.

FBW sangat cocok digunakan pada industri logam yang memproduksi pelat baja berbentuk lembaran. Penyambungan gulungan pelat baja yang satu dengan gulungan berikutnya dilakukan untuk menjamin kelangsungan proses produksi secara kontinu. Persoalan yang sering terjadi pada FBW adalah sering putusnya sambungan pelat di sekitar pengelasan pada saat dilakukan reduksi ketebalan di tendem coll mill (TCM) maupun continous pickling line (CPL). Hal ini tentu merugikan karena dapat menyebabkan terhentinya proses produksi maupun rusaknya peralatan.

Transformasi fasa menyebabkan terjadinya tegangan sisa di permukaan hasil $\mathrm{FBW}^{[5]}$. Parameter dalam proses FBW memiliki pengaruh yang sangat signifikan terhadap sifat mekanisnya. Beberapa parameter proses itu antara lain: mode nyala, panjang nyala, arus nyala, mode hambatan dan panjang hambatan yang digunakan. Dari riset ini diketahui bahwa dengan mengatur paramater pengelasan maka akan diperoleh kualitas pengelasan yang diinginkan ${ }^{[6]}$.

Parameter pengelasan FBW pada $5 \mathrm{~V}, 2 \mathrm{~s}$ flash point menghasilkan kombinasi material yang memiliki kekuatan dan keuletan yang paling baik ${ }^{[7]}$. Hal yang sama juga dilakukan oleh Nwachukwu yang melakukan penelitian tentang pengaruh parameter proses canai seperti suhu canai akhir, persentase deformasi total dan laju regangan canai terhadap baja St60Mn canai panas. Diketahui bahwa laju regangan canai dari $6,02851 \mathrm{~s}^{-1}$ $6,10388 \mathrm{~s}^{-1}$, deformasi total $99 \%$ dan suhu canai akhir 9580C mampu meningkatkan sifat mekanik baja St60 Mn ${ }^{[8]}$.
Pada reduksi canai $35 \%$ terjadi pembentukan dan pertumbuhan lamella kembar dan $\varepsilon$-martensit secara bersamaan sehingga mneghasilkan kombinasi yang baik antara kekuatan dan keuletan serta laju pengerasan yang tinggi ${ }^{[9]}$.

Kekerasan meningkat seiring dengan peningkatan rasio reduksi canai dingin. Pada pengukuran skala nano menunjukkan bahwa modulus elastisitas meningkat seiring dengan peningkatan rasio reduksi ${ }^{[10]}$.

\section{METODE PENELITIAN}

\section{Setting Mesin}

Canai dimaksudkan untuk menipiskan baja strip yang sudah dibersihkan di continuous pickling line (CPL) ketebalan yang diinginkan. Ketebalan baja strip minimum yang dapat dicapai yaitu 0,18 mm. Peralatan ini dikontrol melalui komputer dengan kecepatan canai maksimum 1.980 m/menit dan dapat menipiskan baja lembaran maksimum sampai $92 \%$.

Pengerolan di CTCM menggunakan sistem 4 tingkat, dimana lembaran yang tipis dapat dicanai menjadi tipis lagi. Untuk memperoleh hasil yang optimal, canai disusun secara seri sebanyak lima kali tahapan (stand). Setiap tahapan memiliki reduksi yang berbeda-beda sehingga baja strip bergerak dengan kecepatan yang berbeda.

Pada masing-masing tahapan memiliki 4 buah rol yang terdiri dari dua rol utama dan dua rol pendukung, dengan pengecualian pada rol pertama dan kelima dapat dimodifikasi menjadi 6 buah rol pada masing-masing unitnya. Penambahan 2 rol ini dimaksudkan untuk menghasilkan lembaran yang lebih tipis dan permukaannya lebih halus.

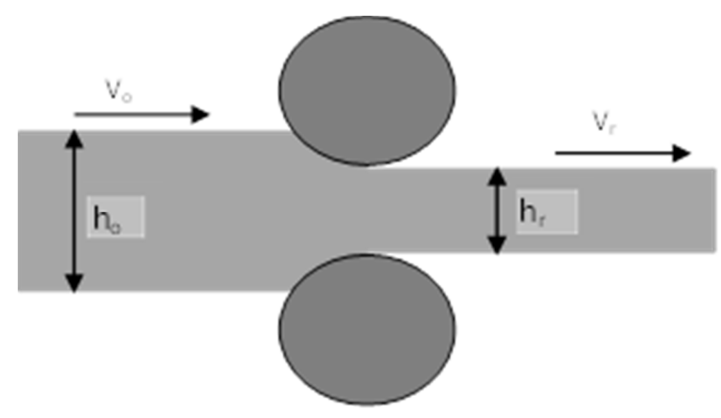

Gambar 1 Skema proses canai

\section{Kodefikasi Sampel Uji}

Spesimen yang digunakan pada penelitian ini adalah baja karbon rendah Standar Nippon Steel Corporation JIS 3141. Ketebalan baja strip awalnya 2,25 mm kemudian dicanai menjadi 0,68, 0.64 dan 
0,60 mm. Untuk memudahkan dalam pembahasan maka diberikan kodefikasi sampel sebagai berikut:

1. Sampel yang tidak mengalami penurunan ketebalan diberikan kode R00.

2. Pengurangan tebal pelat dinyatakan dengan persamaan.

$$
\begin{aligned}
& \mathrm{R}_{\mathrm{xx}}=\frac{\mathrm{h}_{1}-\mathrm{h}_{\mathrm{o}}}{\mathrm{h}_{1}} \times 100 \% \ldots \ldots \ldots \ldots \ldots \ldots \ldots \ldots \ldots \ldots \\
& \mathrm{R}_{00}=\frac{2,25-0,00}{2,25} \times 100 \%=100,0 \% \\
& \mathrm{R}_{69}=\frac{2,25-0,68}{2,25} \times 100 \%=69,78 \% \\
& \mathrm{R}_{71}=\frac{2,25-0,64}{2,25} \times 100 \%=71,56 \% \\
& \mathrm{R}_{73}=\frac{2,25-0,60}{2,25} \times 100 \%=73,33 \%
\end{aligned}
$$

\section{HASIL DAN PEMBAHASAN}

Setelah dilakukan pengamatan, pengukuran dan pengujian masing-masing sampel, baik pada sampel pengelasan sebelum dan sesudah pengerolan pada beberapa. Beberapa hal yang akan dilakukan adalah pembahasan kekerasan, kekuatan tarik, kekuatan luluh, keuletan dan ketahanan terhadap korosi.

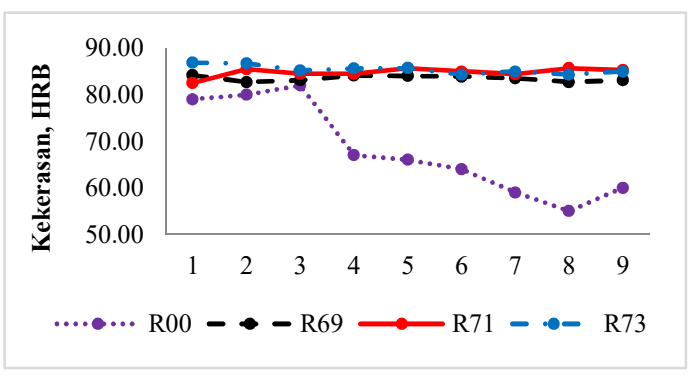

Gambar 2 Distribusi kekerasan daerah lasan

Pengujian kekerasan dilakukan pada spesimen sebelum dan sesudah reduksi ketebalan. Jika diperhatikan maka sampel yang tidak mengalami proses canai memiliki variasi kekerasan yang sangat mencolok antara material induk dengan daerah HAZ dan daerah lasan.

Sedangkan pada baja strip yang mengalami reduksi ketebalan memiliki distribusi kekerasan yang relatif sama di ketiga daerah lokasi uji. Hal ini menjadi indikasi bahwa reduksi ketebalan mampu meningkatkan kekerasan secara merata. Peningkatan kekerasan ini disebabkan adanya penghalusan butir setelah mengalami proses canai.

Gambar 2 menunjukkan bahwa semakin tinggi reduksi ketebalan pelat maka kekerasan material semakin meningkat. Peningkatan ini disebabkan semakin terbatasnya gerak dislokasi. Kehadiran martensit yang dipicu oleh laju regangan juga berkontribusi terhadap peningkatan kekerasan ini.

\section{Pengujian Kekuatan Tarik}

Pengujian tarik dimaksudkan untuk mengetahui daerah elastis dan plastis dari suatu material. Beberapa informasi yang diperoleh dalam pengujian tarik ini adalah kekuatan tarik, kuat luluh, dan keuletannya.

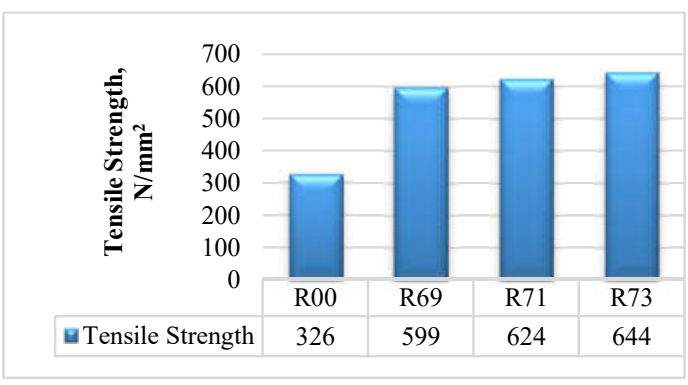

\section{Gambar 3 Korelasi antara persentase reduksi} dan kekuatan tarik

Dari Gambar 3 diketahui bahwa semakin tinggi reduksi ketebalan pelat maka kekuatan tarik baja pelat juga mengalami peningkatan. Peningkatan kekuatan tariknya dapat mencapai $97,55 \%$ dari material tanpa perlakuan canai. Peningkatan kekuatan ini sebanding dengan kekerasannya.

\section{Pengujian Kekuatan Luluh}

Peningkatan kekuatan luluh material dialami oleh material yang memperoleh perlakuan canai. Peningkatan ini mencapai $103,66 \%$ dari 246 $\mathrm{N} / \mathrm{mm} 2$ menjadi $501 \mathrm{~N} / \mathrm{mm} 2$ pada reduksi ketebalan sebesar $73,33 \%$.

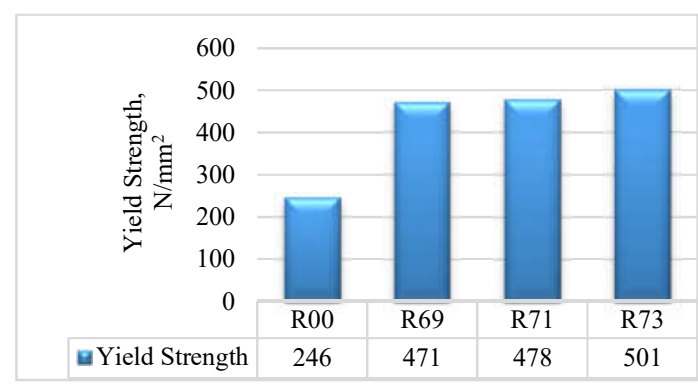

Gambar 4 Korelasi antara reduksi ketebalan dan kekuatan luluh

Dari Gambar 4 menunjukkan bahwa peningkatan kekuatan tarik ini sebanding dengan kekuatan luluhnya.

38 Sunardi, dkk; Pengaruh Reduksi Canai Terhadap Sifat Mekanis Baja Karbon Rendah Dengan Sambungan Flash Butt Welding 


\section{Pengujian Keuletan}

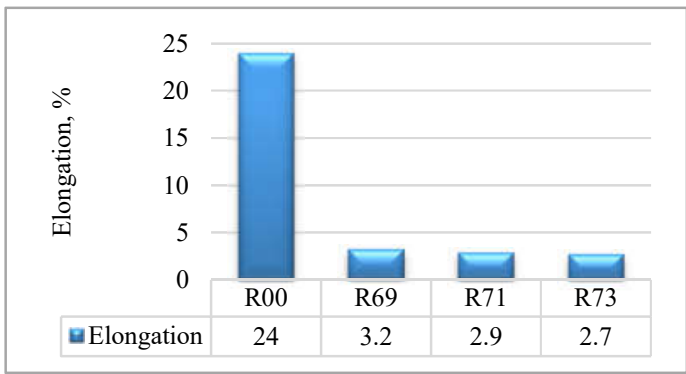

Gambar 5 Korelasi antara reduksi ketebalan dan keuletan

\section{Pengujian Laju Korosi}

Pengujian korosi dilakukan untuk mengetahui nilai laju korosi pada tiap-tiap material. Metode yang dilakukan adalah dengan menggunakan sel tiga elektroda yang menggunakan media cairan $3 \% \mathrm{NaCl}$. Hasil pengujian korosi dinyatakan dengan satuan mpy dan dapat dilihat pada Gambar 6.

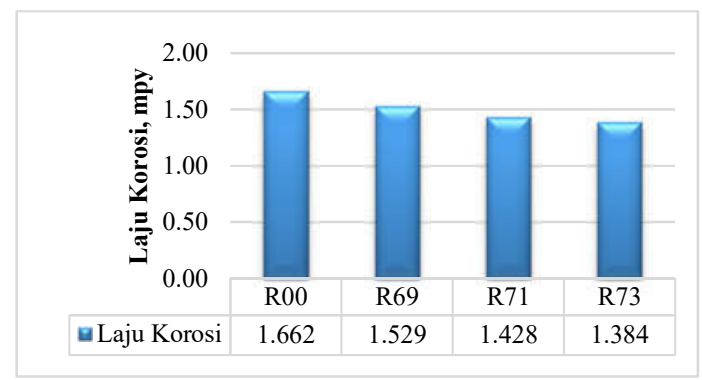

\section{Gambar 6 Korelasi antara reduksi ketebalan dan laju korosi}

Ketahanan korosi meningkat seiring dengan semakin besarnya reduksi ketebalan material, meskipun peningkatan tersebut hanya $16,73 \%$. Penurunan laju korosi ini disebabkan oleh semakin tingginya kekerasan material tersebut. Seperti yang sudah dibahas sebelumnya bahwa reduksi ketebalan ini akan menghambat gerak dislokasi. Kondisi inilah yang menyebabkan laju korosi semakin menurun.

\section{Struktur Mikro}

Pengamatan struktur mikro dilakukan untuk mengetahui seberapa besar perubahan fasa yang dialami oleh material selama proses canai. Di samping itu, struktur mikro akan sangat membantu untuk menganalisis perubahan sifat mekanisnya.

\section{Material Induk}

Sunardi, dkk; Pengaruh Reduksi Canai Terhadap Sifat Mekanis Baja Karbon Rendah Dengan Sambungan Flash Butt Welding
Dari Gambar 7 menunjukkan bahwa tidak terjadi perubahan struktur mikro. Fase yang terbentuk berupa fase ferrite (terang) dan perlit (gelap). Yang terjadi adalah butiran menjadi lebih pipih karena faktor canai. Semakin pipihnya butiran menyebabkan meningkatnya kekuatan material tetapi menurunkan keuletannya.

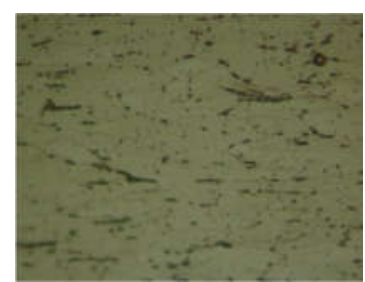

(a)

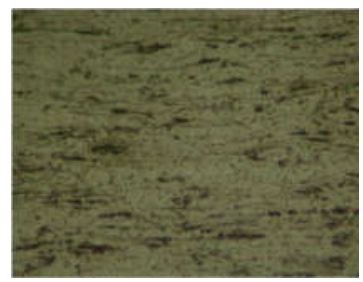

(c)

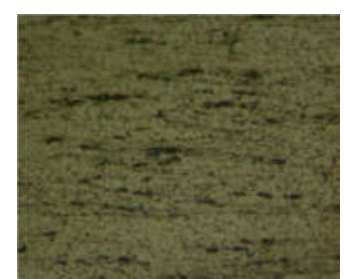

(b)

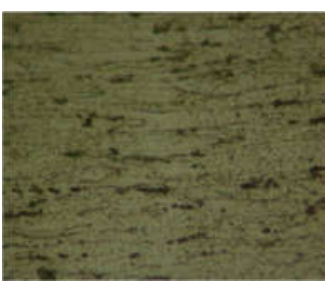

(d)
Gambar 7 Struktur mikro material indusk (a) R00\%, (b) 69\%, (c) $71 \%$ dan (d) $73 \%$

\section{Daerah HAZ}

Di daerah HAZ didominasi oleh ferrit dan perlit. Pada sampel setelah mengalami pengerolan memiliki fenomena yang sama dengan material indusknya yakni semakin pipihnya butiran karena proses canai.

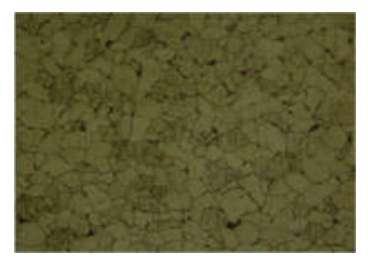

(a)

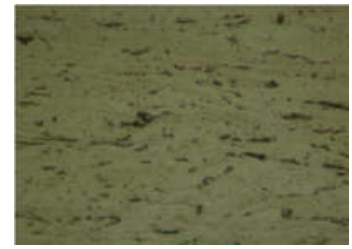

(c)

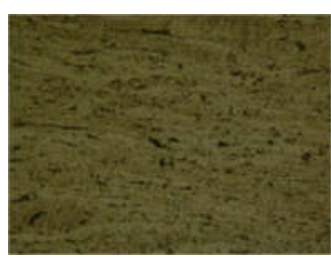

(b)

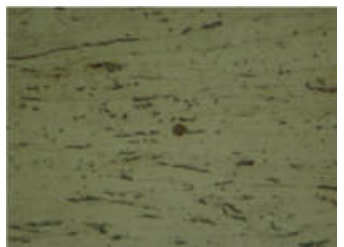

(d) 
Gambar 8 Struktur mikro pada heat affected zone (a) R00\%, (b) $69 \%$, (c) $71 \%$ dan (d) $73 \%$

\section{Daerah Lasan}

Daerah lasan adalah bagian yang mencair saat proses pengelasan. Bagian ini juga memperoleh bagian panas yang sangat tinggi. Struktur yang terbentuk sangat dipengaruhi oleh jumlah panas dan laju pendinginannya. Bentuk struktur mikro yang lebih besar ini yang menyebabkan material memiliki keuletan yang sangat tinggi baik pada material induk, HAZ maupun daerah lasan.

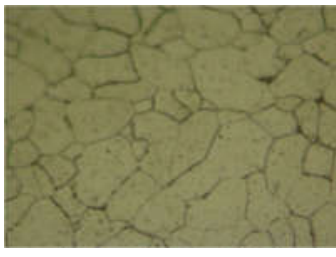

(a)

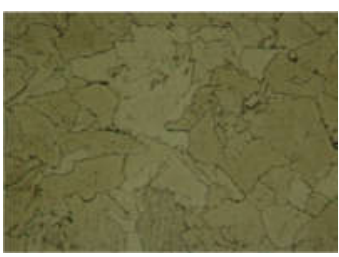

(c)

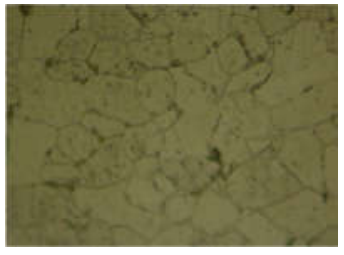

(b)

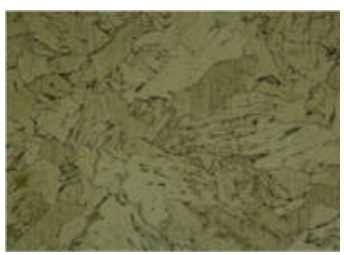

(d)
Gambar 9 Struktur mikro daerah lasan (a) R00\%, (b) 69\%, (c) $71 \%$ dan (d) $73 \%$

\section{KESIMPULAN}

Berdasarkan data hasil penelitian di atas maka dapat disimpulkan sebagai berikut :

1. Semakin tinggi reduksi ketebalan maka semakin tinggi kekerasan, kekuatan tarik, kekuatan luluh, dan ketahanan korosinya, tetapi keuletan material menjadi rendah.

2. Sifat mekanis dan laju korosi yang paling baik terjadi pada sampel yang mengalami reduksi sebesar 73,33\% dengan nilai kekerasan, kekuatan tarik, kekuatan luluh, elongasi dan laju korosi masing-masing sebesar 82,26 HRB, kekuatan tarik $644 \mathrm{~N} / \mathrm{mm} 2$, kekuatan luluh 501 $\mathrm{N} / \mathrm{mm} 2,2,7 \%$ dan 1,384 mpy.

3. Struktur yang terbentuk selama proses canai adalah ferrite dan perlite.

\section{DAFTAR PUSTAKA}

[1] B. B. Singh, K. S. Kumar, V. Madhu, and R. A. Kumar, "Effect of Hot Rolling on Mechanical Properties and Ballistic Performance of High Nitrogen Steel," in Procedia Engineering, 2017, vol. 173, pp. 926-933.

[2] S. K. Ghosh, D. Mahata, R. Roychaudhuri, and R. Mondal, "Effect of rolling deformation and solution treatment on microstructure and mechanical properties of a cast duplex stainless steel," Bull. Mater. Sci., vol. 35, no. 5, pp. 839-846, Oct. 2012.

[3] Suyitno, B. Arifvianto, T. D. Widodo, M. Mahardika, P. Dewo, and U. A. Salim, "Effect of cold working and sandblasting on the microhardness, tensile strength and corrosion resistance of AISI 316L stainless steel," Int. J. Miner. Metall. Mater., vol. 19, no. 12, pp. 1093-1099, Dec. 2012

[4] Sunardi, R. Lusiani, and A. S. Irawan, "Karakteristik Sifat Mekanis dan Struktur Mikro Material Hasil Proses Forging," J. Manutech, vol. 4, no. 1, pp. 12-17, 2012.

[5] C. A. I. Zhipeng, N. Masashi, M. A. Ninshu, Q. U. Yuebo, and C. A. O. Bin, "Residual Stresses in Flash Butt Welded Rail †," vol. 40, no. 1, pp. 79-87, 2011.

[6] D. C. Kim, W. J. So, and M. J. Kang, "Effect of flash butt welding parameters on weld quality of mooring chain," vol. 38 , no. 2 , pp. 112-117, 2009.

[7] R. R. Baracaldo, M. C. Santos, M. Arturo, and A. Echeverría, "Effect of flash butt welding parameters on mechanical properties of wheel rims," vol. 23, no. 01, pp. 51-57, 2018.

[8] P. U. Nwachukwu and O. O. Oluwole, "Effects of rolling process parameters on the mechanical properties of hot-rolled St60Mn steel," Case Stud. Constr. Mater., vol. 6, pp. 134-146, Jun. 2017.

[9] Y. Dong et al., "The Influence of Warm Rolling Reduction on Microstructure Evolution, Tensile Deformation Mechanism and Mechanical Properties of an Fe-30Mn-4Si2Al TRIP/TWIP Steel," Metals (Basel)., vol. 8, no. 10, p. 742 , Sep. 2018.

[10] S. Ağca and G. Çankaya, "Multidisciplinary Studies and Innovative Technologies The Effect of Cold Rolling on Mechanical Properties of Zircaloy-4 †," pp. 29-35, 2017. 